Article

\title{
Impact of Atmospheric Pressure Microwave Plasma Treatment on Quality of Selected Spices
}

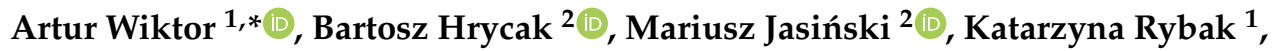 \\ Marek Kieliszek $^{3}{ }^{(D)}$, Karolina Kraśniewska ${ }^{3} \mathbb{D}$ and Dorota Witrowa-Rajchert ${ }^{1}$ (D) \\ 1 Department of Food Engineering and Process Management, Institute of Food Sciences, Warsaw University \\ of Life Sciences, Nowoursynowska 159c, 02-776 Warsaw, Poland; katarzyna_rybak@sggw.edu.pl (K.R.); \\ dorota_witrowa_rajchert@sggw.edu.pl (D.W.-R.) \\ 2 Center for Plasma and Laser Engineering, Institute of Fluid Flow Machinery, Polish Academy of Sciences, \\ 14 Fiszera Str., 80-231 Gdańsk, Poland; bartosz.hrycak@imp.gda.pl (B.H.); mariusz.jasinski@imp.gda.pl (M.J.) \\ 3 Department of Food Biotechnology and Microbiology, Institute of Food Sciences, Warsaw University of Life \\ Sciences-SGGW, Nowoursynowska 159c, 02-776 Warsaw, Poland; marek_kieliszek@sggw.edu.pl (M.K.); \\ karolina_krasniewska@sggw.edu.pl (K.K.) \\ * Correspondence: artur_wiktor@sggw.pl
}

Received: 19 August 2020; Accepted: 23 September 2020; Published: 28 September 2020

check for updates

\begin{abstract}
Current industry needs are related to higher awareness of modern consumers. These consumers are looking for products in which properties such as bioactive compounds are preserved as much as possible. Plasma treatment is one of the most promising nonthermal technologies that can decontaminate food and keep its original properties. Therefore, the aim of this work was to examine the usefulness of atmospheric pressure argon microwave plasma on decontamination of black pepper seeds, allspice berries and juniper berries. The samples were irradiated by plasma for 15-60 s and their physicochemical (dry matter content, water activity, color, total phenolic content, antioxidant activity, piperine content in black pepper seeds) and microbial (bacteria and molds count) quality was evaluated afterwards. Results demonstrated that plasma irradiation for $15 \mathrm{~s}$ was sufficient for partial inactivation of $A$. niger but less effective against the Gram-positive bacterium B. subtilis, regardless of the raw material. At the same time, plasma treatment reduced water activity, which can positively affect further storage of spices. Properly selected plasma parameters may also enhance extractability of phenolics or piperine (from black pepper seeds) and improve antioxidant activity with not very great, but visible, color changes.
\end{abstract}

Keywords: cold plasma; spices; juniper; allspices; pepper; decontamination; quality

\section{Introduction}

The food industry can be characterized as a very competitive branch of the economy. This fact, together with the increasing knowledge of consumers, who pay more attention to their nutrition and care greatly about the environment, stimulates producers and scientists to develop new food processing and preservation technologies. The main aim of food processing is to deliver safe food that can be characterized by good quality. Within the factors that can be considered a hazard, microbial growth can be distinguished. Conventionally, inactivation of microbiota can be achieved by thermal methods such as pasteurization or sterilization [1-4]. Although these techniques are effective considering their lethal effect on microorganisms' growth, they also cause degradation of many thermolabile compounds, with nutritional activity being of paramount importance [5,6]. Therefore, new technologies start to play very important roles, since they allow reduction of microbial contamination and, at the same time, they can maintain the quality of processed food. Among these emerging methods, a few need to be 
distinguished such as pulsed electric field, ultrasound, high hydrostatic pressure and pulsed light cold plasma [7-10]. Moreover, cold plasma is also considered a very promising method that can achieve the abovementioned technological effects with minimal impact on food quality [11].

In general, nonequilibrium plasmas under atmospheric pressure have been used for various purposes [11-17] such as material processing (e.g., etching, deposition, polymer surface activation), food processing, surface decontamination (e.g., sterilization of surgical instruments) and decomposition of gases and liquids (e.g., production of valuable chemicals, environmental applications).

Atmospheric plasma can be generated using different methods. For instance, it can be generated using microwaves [18] or a dielectric barrier discharge (DBD) system [19]. The utilization of microwaves for generation of plasma is becoming increasingly popular. The microwave plasma is characterized by a wide range of temperatures. Applications of atmospheric pressure microwave plasma are very wide. Such plasmas can be used for gas processing [20,21], surface modification [22] or for biomedical decontamination [14,23-25]. Because of the specific determinants of microwave generated plasma, especially the fact that it can operate under atmospheric pressure, it can be used in the food industry. Publications show that treatment performed with this plasma can be used in decontamination [26], degradation of mycotoxins [27] and indirect treatment of meat [28] and black pepper [29].

In the case of food processing, plasma is generated in a discharge volume and makes contact with the treated food surface. Fast electrons, ions and free radicals, as well as electromagnetic radiation in the UV/VIS spectrum, are then transferred to the plasma-surface interface where they initiate basic processes such as etching, recombination, de-excitation and re-emission from solids [13]. As a result, plasma treatment can decontaminate food surfaces and change their physicochemical properties, leading to extended food shelf life.

The aim of this work was to examine the usefulness of atmospheric pressure argon microwave plasma, in the unique form of a plasma sheet, on the decontamination of selected spices (pepper seeds, juniper and allspices berries), and to evaluate the impact of such treatment on the physicochemical properties of used materials.

\section{Materials and Methods}

\subsection{Material Preparation}

\subsubsection{Treated Material}

Whole black pepper seeds, whole allspice berries and whole juniper berries packed in barrier pouches were purchased in a local supermarket (Warsaw, Poland) and used in the study. Samples of each raw material came from the same manufacturer and production batch.

\subsubsection{Culture Preparation}

The bacterial strain Bacillus subtilis ATCC 6633 and the mold strain Aspergillus niger ATCC 9142 were obtained from the pure cultures collection of the Department of Food Biotechnology and Microbiology (WULS-SGGW, Warsaw, Poland).

The cultures of Bacillus subtilis ATCC 6633 were kept frozen in glycerol stocks at $-80^{\circ} \mathrm{C}$. The strain was prepared to grow in Nutrient Broth (NB, POCH S.A. Gliwice, Poland) at $37^{\circ} \mathrm{C}$ for $24 \mathrm{~h}$ in an aerobic condition. After the first propagation, the bacteria were transferred and cultured onto nutrient agar (NA, POCH S.A. Gliwice, Poland) and incubated at $37^{\circ} \mathrm{C}$ for $24 \mathrm{~h}$. Next, the bacterial culture was diluted in sterile saline water $(0.85 \% \mathrm{NaCl}$, POCH S.A. Gliwice, Poland) to the adjusted equivalent of $0.5^{\circ}$ McFarlanda (Densimat, Biomérieux Biotechnology, Warsaw, Poland), which was used to obtain the final concentration of $1 \times 10^{8} \mathrm{cfu} / \mathrm{mL}$.

The suspension of the sporulating fungal strain Aspergillus niger was stored in glycerol stock at $-80^{\circ} \mathrm{C}$ and subsequently cultured on Wort Agar (Merck, Warsaw, Poland). After 7 days of incubation at $25^{\circ} \mathrm{C}$, the spores/mycelium of the mold culture were transferred onto fresh Sabourand agar with 
chloramphenicol medium (SA, Sabouraud Agar, POCH S.A. Gliwice, Poland) and subsequently cultured to achieve spores (approximately 7 days) at $25^{\circ} \mathrm{C}$. The concentration of chloramphenicol was $0.050 \mathrm{~g} / \mathrm{L}$. The spores were then harvested by flooding the surface of the mycelium with saline water containing $0.1 \%$ Tween 80 (Sigma-Aldrich, Poznan, Poland). The final spore concentration was determined microscopically using a counting Thoma chamber to achieve a spore concentration of $1 \times 10^{7} \mathrm{cfu} / \mathrm{mL}$.

\subsubsection{Culture Preparation}

Each spice sample (juniper, pepper and allspice) was inoculated using a bacterial or fungal culture suspension. The suspension of $B$. subtilis cell and A. niger spores were individually prepared in a sterile bag with approximate concentrations of $10^{8} \mathrm{cfu} / \mathrm{mL}$ and $10^{7} \mathrm{cfu} / \mathrm{mL}$, respectively. Spice samples were then dipped in the suspension and each of the bags were shaken at $200 \mathrm{rpm}$ for $20 \mathrm{~min}$ on a rotary platform to ensure homogeneous distribution of the inoculum onto the surfaces. Next, for better microorganism attachment, the inoculated spice samples were air-dried in a laminar flow cabinet at room temperature (Esco, Singapore, Singapore) to complete dryness (approximately $1 \mathrm{~h}$ ). The inoculated spices were assessed for initial microbial content and the evaluation confirmed $1 \times 10^{5}$ $\mathrm{cfu} / \mathrm{g}$ (bacteria) and $1 \times 10^{6} \mathrm{cfu} / \mathrm{g}$ of fungal populations.

Inoculated spice samples were aseptically placed in sterile Petri dishes and treated by four different parameters of cold plasma, as described further.

\subsection{Plasma Sources and Plasma Treatment}

For treatment of the selected spices, a unique microwave $(2.45 \mathrm{GHz})$ plasma source (MPS) operating at atmospheric pressure argon [30,31] was used in these investigations. In contrast to previous MPSs operating at atmospheric pressure, which delivered plasmas in the form of cylindrical plasma columns or flames, the MPS used in the presented study generated a very convenient plasma sheet. Such a shape of plasma can be easily implemented into a technology line (i.e., over the conveyor belt). This type of MPS may be based on a rectangular waveguide or on a strip-line structure [32]. In this experiment, we used a setup based on a WR 340 standard rectangular waveguide (Figure 1). Argon plasma was generated inside a flat quartz box and protruded out of the box. The flat quartz box was inserted into the waveguide through rectangular slits in the section of reduced height of the MPS. As a protection from microwave leakage, the discharge quartz box was surrounded by metal shielding. The working gas (argon) was introduced into the quartz box by two opposite ducts placed in its upper part. The MPS had an integrated three-stub tuner to match the impedance. Using the tuner, the microwave reflected power was less than $5 \%$ of the microwave forward power and there was no need to use the protection isolator. Microwaves were generated by a standard magnetron (CEFEMO 2M240H), commonly used in kitchenette microwave ovens. The magnetron was powered from a Dipolar MagDrive (Sweden) power supply. The microwave power absorbed by the plasma was $600 \mathrm{~W}$. At the microwave power (incident power-reflected power) absorbed by the plasma at $600 \mathrm{~W}$, the device consumed approximately $920 \mathrm{~W}$ of electrical power from the power grid. The argon flow rate was set at $20 \mathrm{~L} / \mathrm{min}$. Under these conditions, the plasma sheet outside the box was about $50 \mathrm{~mm}$ width, 10mm length and $1 \mathrm{~mm}$ thick, and the temperature of the plasma was about 900-950 K [25]. The treated spices were placed on a Petri dish on the motorized (with stepper motor) linear stage. The linear stage was placed $20 \mathrm{~mm}$ below the open side of the quartz box (Figure 2). The diameter of the Petri dish was $60 \mathrm{~mm}$. The linear stage moved the Petri dish so that the plasma scanned its area from one side to the other. One full scan of the Petri dish's area lasted $15 \mathrm{~s}$. The samples were treated by plasma from 15 (single scan) up to 60 (four scans) seconds. 


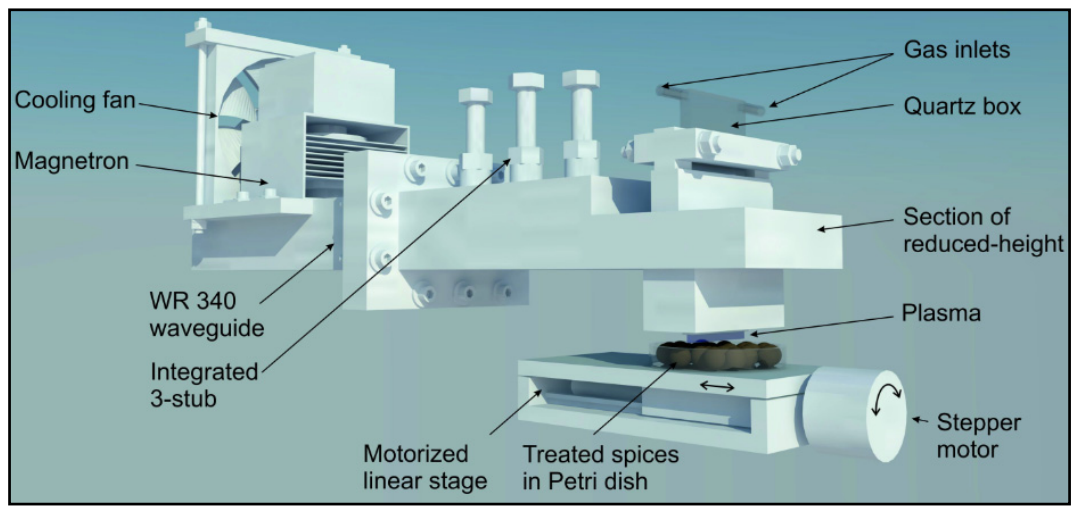

Figure 1. Setup for microwave plasma treatment of selected spices.

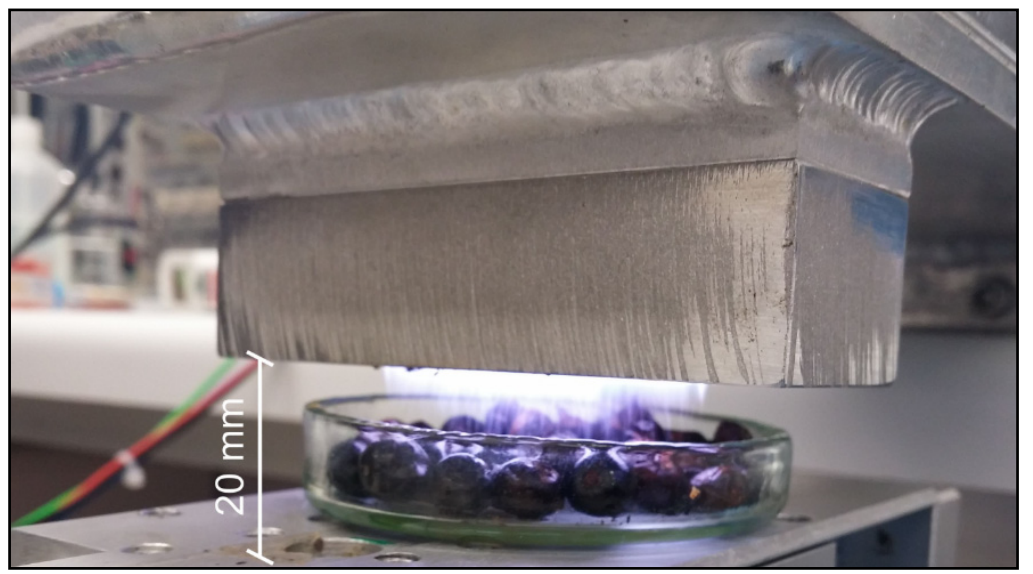

Figure 2. Photo of plasma treatment of juniper berries.

\subsection{Microbiological Analysis}

After treatment, $10 \mathrm{~g}$ of each spice sample were transferred to a sterile stomacher bag (BagFilterP, Labindex, Poland) filled with $90 \mathrm{~mL}$ of sterile $0.1 \%$ peptone water (POCH S.A. Gliwice, Poland). The samples were rinsed with the tested solution with shaking at $200 \mathrm{rpm}$ for $10 \mathrm{~min}$ on a rotary platform (SM-30 Control E. Büchler, Germany) to achieve well-washed bacterial cell and fungal spores from the surface of the spices. To assess bacteria, the suspension was serially diluted in sterile saline water $(0.85 \% \mathrm{NaCl}$ POCH S.A. Gliwice, Poland), then $1 \mathrm{~mL}$ of sample was poured in the plate, selective nutrient agar medium (Nutrient Agar) was added, and the sample incubated at $37^{\circ} \mathrm{C}$ for $24 \mathrm{~h}$. The fungi were serially diluted and poured onto Sabouraund agar with chloramphenicol medium (SA, Sabouraud Agar, POCH S.A. Gliwice, Poland). The plates were incubated at $20^{\circ} \mathrm{C}$ for $72 \mathrm{~h}$. All tests were run in triplicate. Microbial counts were expressed as log cfu/g.

\subsection{Total Phenolic Content (TPC)}

Total phenolic content (TPC) was determined according to the Folin-Ciocalteu methodology [33] with our own modifications. Whole pepper seeds, juniper or allspices berries were milled according to the protocol described in PN-ISO 2825 and then subjected for polyphenolic compounds extraction performed with $80 \%$ ethanol solution. Two independent ethanol extracts were prepared for each variant of the experiment. To determine the TPC, $0.5 \mathrm{~mL}$ of extract was added to a flask containing $30 \mathrm{~mL}$ of distilled water and mixed with $2.5 \mathrm{~mL}$ of Folin-Ciocalteau reagent. After $5 \mathrm{~min}, 2 \mathrm{~mL}$ of $1.7 \mathrm{M}$ sodium carbonate was added. The mixture was well stirred, filled with distilled water up to $50 \mathrm{~mL}$ of volume and left for $1 \mathrm{~h}$ in darkness. After incubation the absorbance against a blank sample (without extract) at $750 \mathrm{~nm}$ was measured using a He $\lambda$ ios $\gamma$ ThermoSpectronic spectrophotometer (Thermo Electron Corporation, Waltham, MA, USA). TPC was expressed in terms of gallic acid equivalents 
concentration [mg GAE/g d.m.] on the basis of a standard curve. The measurements were done in two repetition for each extract.

\subsection{Antioxidant Activity}

Free radical scavenging was assessed according to a modified methodology proposed by Newerli-Guz [34] using 2,2-diphenyl-1-picrylhydrazyl (DPPH) (Sigma Aldrich, St. Louis, MO, USA) and 2,2'-azino-bis(3-ethylbenzothiazoline-6-sulfonic acid (ABTS) (Sigma Aldrich) as a source of the free radicals. A sample extract $(1 \mathrm{~mL})$, prepared as mentioned in Section 2.4., was added into $2 \mathrm{~mL}$ of DPPH or ABTS methanol solution. After good stirring, and $1 \mathrm{~h}$ storage in darkness, absorbance was measured

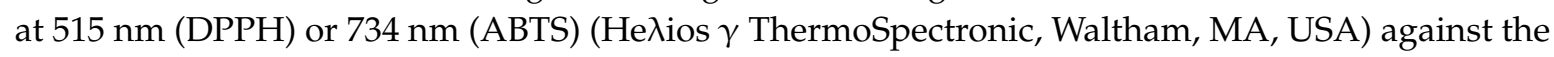
blank sample (the extract was replaced by $1 \mathrm{~mL}$ of $99 \%$ methanol solution). The measurements were conducted in triplicate for each material extract. Antioxidant activity was expressed according to the following formula:

$$
A A=\left(1-\left(\frac{A b s_{S}}{A b s_{F R}}\right)\right) \cdot 100 \%
$$

where: $A b s_{S}$ is the absorbance of sample extract mixed with DPPH or ABTS after $1 \mathrm{~h}$ of incubation and $A b s_{F R}$ is the absorbance of the blank sample mixed with DPPH or ABTS after $1 \mathrm{~h}$ of incubation.

\subsection{Piperine Content in Black Pepper}

Piperine content was evaluated according to the method described in PN-A-86965:1997. This method depends on extraction with ethanol under a reflux condenser and spectrophotometric measurement at $343 \mathrm{~nm}$. The measurements were done in three repetitions for each batch of plasma-treated black pepper. The results were expressed as percentage content of dry matter.

\subsection{Color Measurement}

The color of the samples, placed in a special petri dish $(\mathrm{d}=30 \mathrm{~mm})$ which allowed a light beam to pass through, was measured by reflectance using a Konica-Minolta CM-5 (Osaka, Japan) Chroma Meter. CIE (Comission Internationale de $1^{\prime}$ Eclairage) Standard Illuminate D65, di: $8^{\circ}$ (diffuse illumination $/ 8^{\circ}$ viewing angle), CIE: $2^{\circ}$ standard observer and a $30 \mathrm{~mm}$ measuring area was used. The measurement was done in 12 repetitions. Before each measurement, the device was calibrated with the patterns delivered by the producer.

The $\Delta \mathrm{E}$ (total color difference) and color saturation were calculated on the basis of the following equations:

$$
\begin{gathered}
\Delta E=\sqrt{\left(\Delta L^{*}\right)^{2}+\left(\Delta a^{*}\right)^{2}+\left(\Delta b^{*}\right)^{2}} \\
C=\sqrt{\left(a^{*}\right)^{2}+\left(b^{*}\right)^{2}}
\end{gathered}
$$

where $\Delta L^{*}, \Delta a^{*}, \Delta b^{*}$ are the differences of mean $L^{*}, a^{*}$ and $b^{*}$ parameters, respectively, between intact and plasma treated samples.

\subsection{Water Activity}

Water activity of analyzed samples was measured using AQUALAB (Decagon Devices, Pullman, WA, USA) at a temperature of $25{ }^{\circ} \mathrm{C}$ shortly after the treatment. The samples were put into the measurement cell and the readings were done after stabilization of conditions inside the cell. The measurement was done in triplicate.

\subsection{Dry Matter Content}

Dry matter content was assessed according to PN-A-79011-3:1998. The measurement was done in triplicate for each investigated variant. 


\subsection{Temperature Measurements}

Temperature of the surface was measurement directly after each plasma applications using an IR-thermometer (62 Max, Fluke, Everett, WA, USA).

\subsection{Scanning Electron Microscope (SEM) Imaging}

The morphology of the black pepper seeds was evaluated using an SEM microscope (TM3000, Hitachi, Chiyoda City, Tokyo, Japan) using $\times 100$ magnification. The samples for study were randomly selected and cut into half using a razor blade. Before imaging, the samples were covered with gold to facilitate the imaging.

\subsection{Statistical Analysis}

ANOVA at $\alpha=0.05$ and the Tukey test were used to evaluate significant differences between investigated samples. The statistical analysis was carried out using STATISTICA 13 (Statsoft, Tulsa, OK, USA) and Excel (Microsoft, Albuquerque, NM, USA) software. Significant differences between investigated samples, based on the Tukey test results, were indicated by different small letters $(a, b$, c ... ) , capital letters (A, B, C ... ) or capital letters in brackets ([A], [B], [C] .. ) for different spices species (black pepper seeds, juniper berries and allspices berries, respectively).

\section{Results and Discussion}

\subsection{Dry Matter Content and Water Activity}

Dry matter content and water activity of plasma treated spices is presented in Figures 3 and 4. Both dry matter content and water activity changed with treatment time, and the changes depended on the type of raw material that was subjected to treatment. The highest changes of both water activity and dry matter content were found for the longest plasma application times regardless of the type of spice. For example, allspices berries after $60 \mathrm{~s}$ of treatment contained $0.91 \mathrm{~kg} \mathrm{~d} . \mathrm{m} . / \mathrm{kg}$ of dry matter, which was around $7 \%$ more than the dry matter content obtained for untreated samples. The increment of dry matter content registered for juniper berries and black pepper seeds was equal to 2 and $3.5 \%$, respectively. The changes of dry matter content were related to evaporation of water after the plasma treatment, since the temperature of the samples after radiation were raised (Figure 5). Similar findings were reported by Kriz et al. [35] who studied plasma treatment of grain and Selcuk et al. [36] who studied impact of plasma on grain and legumes. Moreover, all the changes were significantly $(p<0.05)$ different in comparison to control samples.

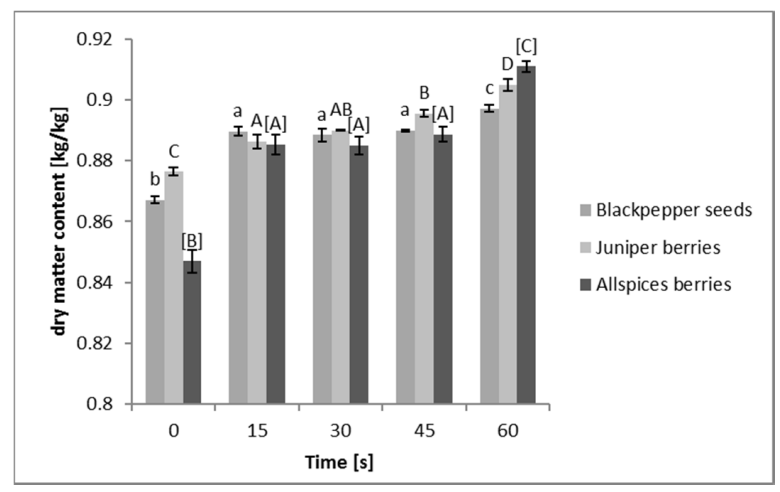

Figure 3. Dry matter content changes after plasma treatment. The significant differences between investigated samples, based on the Tukey test results, are indicated by different small letters (a, b, c . . ), capital letters (A, B, C ... ) or capital letters in brackets $([\mathrm{A}],[\mathrm{B}],[\mathrm{C}] \ldots$ ) for different spice species (black pepper seeds, juniper berries and allspices berries, respectively). $n=3$. 


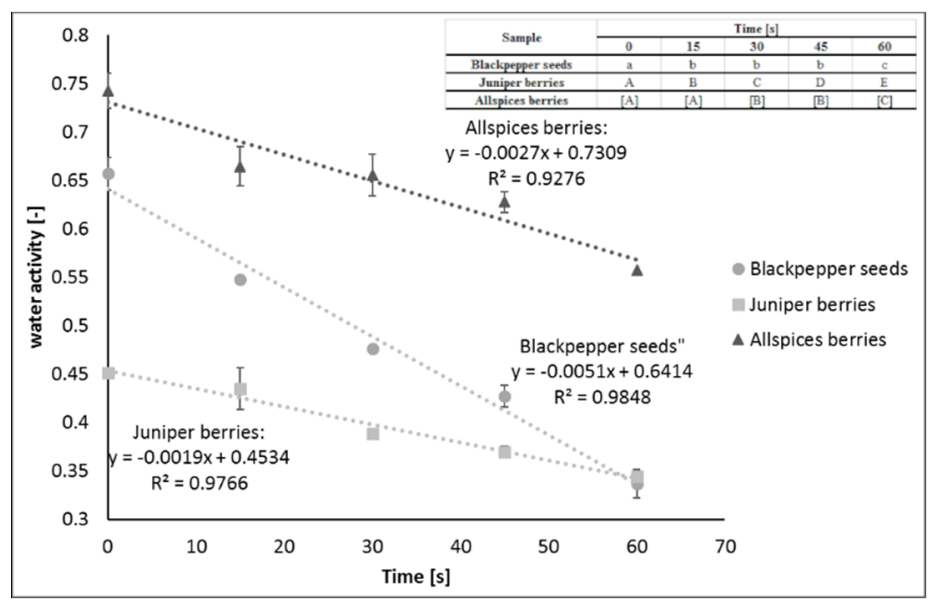

Figure 4. Water activity changes after plasma treatment. Significant differences between investigated samples, based on the Tukey test results, are indicated by different small letters ( $a, b, c . .$.$) , capital$ letters (A, B, C ... ) or capital letters in brackets ([A], [B], [C] ... ) for different spice species (black pepper seeds, juniper berries and allspices berries, respectively). $n=3$.

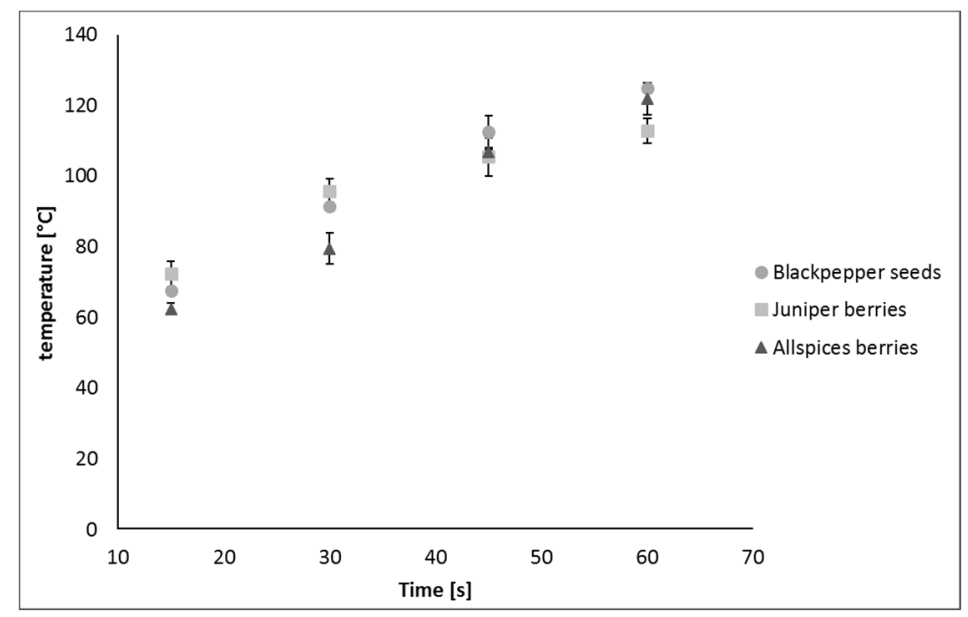

Figure 5. Changes of samples surface temperature directly after plasma application. $n=3$.

Water activity of untreated raw materials was equal to $0.45,0.66$ and 0.74 for juniper berries, black pepper seeds and allspices berries, respectively (Figure 4). Water activity changes followed a pattern opposite to the changes of dry matter content, which was also related to the changes of temperature and enhanced water evaporation. Samples with higher dry matter content were characterized by lower activity. The lowest water activity levels were found for samples subjected to the longest treatment. Among all samples, black pepper seeds and juniper berries treated for $60 \mathrm{~s}$ of plasma radiation exhibited the lowest water activity, which was equal to 0.34 . At the same time, allspices berries treated for the same time had water activity level of 0.56 . In almost all cases, even the lowest treatment time differed significantly from the material in control samples. Only in the case of allspices berries did plasma irradiation lasting $15 \mathrm{~s}$ not cause any significant decrease of water activity. In fact, materials subjected for the longest plasma treatment differed significantly from all other samples regardless of the type of spice. The lowering of water activity by means of plasma application was also reported by Kim et al. [37] for red pepper powder treated by microwave-powered cold plasma. The decrease of water activity was strongly related to the dry matter content and water evaporation during the treatment. It is also worth emphasizing, that the kinetics of water activity decrease was different for each raw material subjected to treatment. The fastest changes were noted for the black pepper seeds, followed by allspices and juniper berries, as indicated by the parameters of linear equations appended to Figure 4 . 


\subsection{Microorganism Growth}

Plasma activity on black pepper seeds for $15 \mathrm{~s}$ caused a reduction of the initial Aspergillus niger number by about two logarithmic cycles compared to the control (Figure 6A). The prolongation of the exposure time over $45 \mathrm{~s}$ in all spices (black pepper seeds, juniper and allspices berries) resulted in complete elimination of $A$. niger mold number (Figure 6B,C). In the case of the Gram-positive Bacillus subtilis bacteria, there was no large decrease in the number of microorganisms in each time variant. Probably, unfavorable conditions could have affected the formation of the sporulating form of B. subtilis, which allowed the bacteria to survive extremely unfavorable conditions.

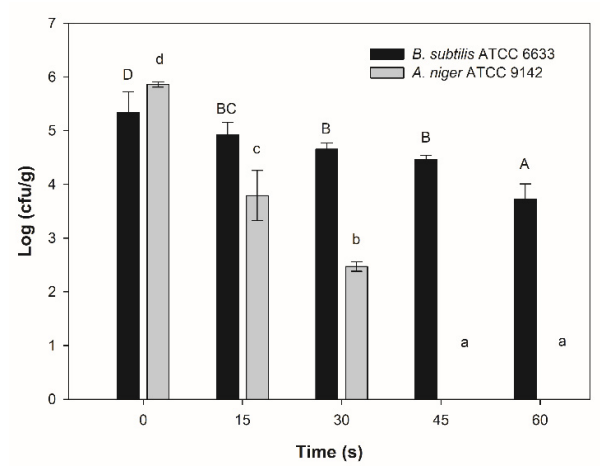

(A)

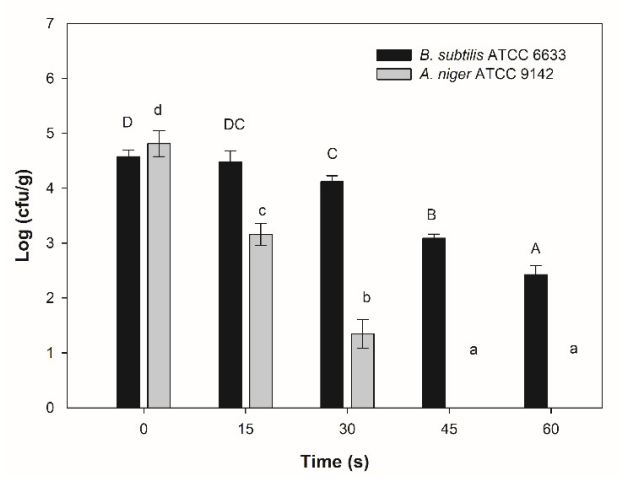

(B)

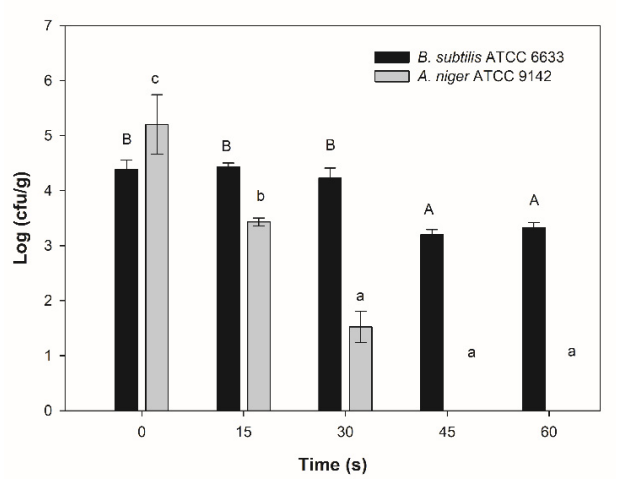

(C)

Figure 6. The results of microbiological analysis of untreated and plasma-treated inoculated (A) black pepper seeds, (B) juniper berries and (C) allspices berries. The same capital or small letters indicate homogenous groups $(\alpha=0.05)$ for bacteria and molds growth results, respectively. $n=3$. 
Data provided by Purevdorj et al. [38] showed that the use of plasma resulted in a reduction in the number of Escherichia coli microorganisms relative to a control by approximately 4.4 logs for $30 \mathrm{~min}$. Operation of microwave plasma for microorganisms is likely to cause digestion of the wall and membrane assembly of microorganisms because of both the large amount of highly reactive molecules in the plasma and the high temperature. As a consequence, this affects leakage into the extracellular environment of cell organelles. In addition, the formation of volatile compounds may have an impact on these phenomena, as a result of a slow combustion process using oxygen atoms or plasma radicals [39]. The work presented by Baier et al. [40] showed that the number of E. coli bacteria in lettuce was reduced by $3.6 \log \mathrm{cfu} / \mathrm{cm}^{2}$ by treatment with an atmospheric stream of cold plasma. Treatment of red chicory leaves contaminated with L. monocytogenes with a cold plasma stream (air, 15 $\mathrm{kV}, 30 \mathrm{~min}$ ) reduced the number of microorganisms by approximately $2.2 \log \mathrm{cfu} / \mathrm{cm}^{2}$ [41]. In a similar experiment Ziuzina et al. [42] showed that plasma duration $(60 \mathrm{~s}$, air, $70 \mathrm{kV})$ reduced the number of Salmonella typhimurium on tomatoes from $6.3 \mathrm{log}$ cfu/sample to undetectable levels. In studies presented by Hertwig et al. [29], the action of plasma $(30 \mathrm{~min}$ ) reduced the number of Bacillus subtilis and Bacillus atrophaeus spores by 2.4 and 2.8 logs, respectively. In addition, Handorf et al. [43] showed a reduction in colony-forming units for p.fluorescens of $4 \log$ steps, and a reduction of 3 log steps in Listeria monocytogenes suspension cultures. In summary, the action of plasma inhibits the growth of various groups of microorganisms. In the current research, the plasma treatment led to the increase of temperature as presented in Figure 5. This elevation of temperature, in addition to other previously presented reasons, contributed to the microorganisms' population decrease.

\subsection{Color}

Table 1 shows the optical properties of spices exposed to cold plasma treatment. The lightness $\left(L^{*}\right)$ of black pepper seeds and juniper berries decreased with treatment time. No such behavior was found for allspices berries in which the changes of the $L^{*}$ parameter were significant only in the case of the treatment that lasted $45 \mathrm{~s}$. The values of the parameters which represent the share of red-green colors were higher for plasma treated materials in comparison to the reference samples. For example, $a^{*}$ chromametric values were equal to 2.43 and 3.14 for untreated and $60 \mathrm{~s}$ irradiated black pepper seeds, respectively. In turn, $b^{*}$ color parameter changes depended on the type of investigated raw materials. Plasma treatment caused an increase of $b^{*}$ in the case of black pepper seeds and allspices berries, but the changes registered for juniper berries were ambiguous. Similar findings were reported for black pepper seeds treated by direct plasma generated with a radio frequency jet by Hertwig et al. [29]. The values of $\Delta E$ indicated that, in most cases, the change in color was distinct $(\Delta E>3.5)$ but in some cases plasma treatment led to smaller color changes, which, nevertheless, could be noticed even by an inexperienced observer $(2<\Delta E<3.5)$ [44]. Literature data about the impact of plasma on color of different food materials is ambiguous. For instance, Zhang et al. [45] reported that exposition of chili pepper samples to atmospheric air plasma for $60 \mathrm{~s}$ did not cause any significant change of $L^{*}$ or $b^{*}$ but led to a decrease of the red/green chromametric parameter. Moreover, Lacombe et al. [46], who studied the impact of plasma treatment on the color of blueberries, reported that longer plasma treatment times may lead to darkening of blueberries instead of the bleaching that was expected due to anthocyanin degradation. In turn, Sarangapani et al. [47] demonstrated that cold plasma did not cause any significant changes of color of blueberries. The research performed by Won et al. [48] on microwave-powered cold plasma treatment of mandarin showed that color of the tissue did not change after plasma treatment The effect of plasma on color seems to depend strongly on the type of plasma treatment and the properties of the material, among which the moisture content and the type of pigment play the most import role. 
Table 1. The color of different spices subjected to plasma treatment. The same letters indicate homogenous groups $(\alpha=0.05)$.

\begin{tabular}{|c|c|c|c|c|c|}
\hline Material & Time [s] & $L^{*}$ & $a^{*}$ & $b^{*}$ & $\Delta \mathrm{E}$ \\
\hline \multirow{5}{*}{ Black pepper seeds } & 0 & $16.81 \pm 0.39 \mathrm{a}$ & $2.43 \pm 0.22 \mathrm{a}$ & $3.85 \pm 0.26 \mathrm{a}$ & 0 \\
\hline & 15 & $15.55 \pm 0.41 \mathrm{~b}$ & $3.04 \pm 0.31 \mathrm{~b}$ & $5.4 \pm 0.75 b$ & 4.04 \\
\hline & 30 & $15.06 \pm 0.42 b$ & $3.3 \pm 0.24 \mathrm{~b}$ & $6.04 \pm 0.32 b$ & 7.28 \\
\hline & 45 & $15.24 \pm 0.40 \mathrm{~b}$ & $3.15 \pm 0.24 b$ & $5.86 \pm 0.40 \mathrm{~b}$ & 6.13 \\
\hline & 60 & $14.92 \pm 0.41 \mathrm{~b}$ & $3.14 \pm 0.29 \mathrm{~b}$ & $5.86 \pm 0.34 \mathrm{~b}$ & 6.42 \\
\hline \multirow{5}{*}{ Juniper berries } & 0 & $15.57 \pm 0.59 \mathrm{~A}$ & $3.57 \pm 0.38 \mathrm{~A}$ & $4.11 \pm 0.88 \mathrm{~A} \mathrm{~B}$ & 0 \\
\hline & 15 & $13.4 \pm 0.73 \mathrm{CD}$ & $4.45 \pm 0.42 \mathrm{~B} \mathrm{C}$ & $5.37 \pm 0.83 \mathrm{~B} \mathrm{C}$ & 4.52 \\
\hline & 30 & $12.64 \pm 1.02 \mathrm{~B} \mathrm{C}$ & $4.42 \pm 0.6 \mathrm{~B} \mathrm{C}$ & $4.1 \pm 0.70 \mathrm{~A}$ & 3.66 \\
\hline & 45 & $14.17 \pm 1.0 \mathrm{D}$ & $4.96 \pm 0.09 \mathrm{C}$ & $5.88 \pm 0.55 \mathrm{C}$ & 6.45 \\
\hline & 60 & $11.84 \pm 0.78 \mathrm{~B}$ & $4.15 \pm 0.56 \mathrm{~A} \mathrm{~B}$ & $3.92 \pm 0.65 \mathrm{~A}$ & 4.1 \\
\hline \multirow{5}{*}{ Allspices berries } & 0 & $\begin{array}{c}23.84 \pm 0.63[\mathrm{~A}] \\
{[\mathrm{B}]}\end{array}$ & $6.28 \pm 0.25[\mathrm{~A}]$ & $10.64 \pm 0.53[\mathrm{~A}]$ & 0 \\
\hline & 15 & $23.28 \pm 0.41[\mathrm{~A}]$ & $6.96 \pm 0.15[\mathrm{~B}]$ & $\begin{array}{c}12.06 \pm 0.33[\mathrm{~B}] \\
{[\mathrm{C}]}\end{array}$ & 3.02 \\
\hline & 30 & $\begin{array}{c}23.76 \pm 0.27[\mathrm{~A}] \\
{[\mathrm{B}]}\end{array}$ & $7.06 \pm 0.21[\mathrm{~B}]$ & $12.49 \pm 0.33[\mathrm{C}]$ & 4.09 \\
\hline & 45 & $22.31 \pm 0.7[\mathrm{C}]$ & $6.74 \pm 0.27[\mathrm{~B}]$ & $\begin{array}{c}11.49 \pm 0.66[\mathrm{~A}] \\
{[\mathrm{B}]}\end{array}$ & 2.46 \\
\hline & 60 & $24.24 \pm 0.65[\mathrm{~B}]$ & $6.98 \pm 0.23[\mathrm{~B}]$ & $12.94 \pm 0.72[\mathrm{C}]$ & 6.18 \\
\hline
\end{tabular}

Significant differences between investigated samples, based on the Tukey test results, are indicated by different small letters $(a, b, c \ldots)$, capital letters $(A, B, C \ldots)$ or capital letters in brackets ([A], [B], [C] ...) for different spices species (black pepper seeds, juniper berries and allspices berries, respectively). $n=12$.

\subsection{Total Polyphenolc Content and Antioxidant Activity}

The highest number of phenolic compounds was found in allspices berries (Figure 7). This raw material contained between 7017 and 12,595 mg GAE/100 g d.m. of phenolics, depending on the treatment parameters. In comparison, total polyphenol content measured for black pepper seeds and juniper berries stayed in a range of 1304-3102 mg GAE/100 $\mathrm{g}$ d.m. The plasma effect on phenolics was ambiguous but, in most cases, it changed significantly $(p<0.05)$ the total phenol concentrations of allspices and black pepper seeds. No relevant changes were observed for all plasma treated juniper berries and black pepper seeds treated by $60 \mathrm{~s}$. In the case of allspices, the shortest plasma irradiation led to a significant increment of the phenolics whereas, in the case of other materials, total polyphenol content did not change or decreased. Such results may be related to modification of the superficial structure of the allspices berry, which allowed the phenols to be extracted more efficiently, and most probably the shortest action of the reactive chemical species, which can cause oxidation. Such an explanation may be controversial, especially when considering the results for the longest treatment time, which should have led to the highest concentration of reactive species. However, the extractability of phenolics is a superposition of, for instance, structure modification that can improve mass transfer, and other factors, such as the presence of oxidative agents or elevated temperature, that can decrease the content. Therefore, it can be assumed that moderate treatment times were related to higher degradation due to oxidation of phenolics, which was not compensated by structure modification or formation of new compounds that can react with Folin-Ciocalteu (F-C) reagent. Therefore, it is recommended for future research to study the phenolics profile changes after plasma treatment of spices. It is also worth emphasizing that similar findings were reported previously for other nonthermal processing methods such as a pulsed electric field [49]. The minimal effect of plasma treatment on phenolics content has been reported by Tappi et al. [50] for fresh-cut apples. Other reports indicate that plasma radiation can increase the concentration of phenolic compounds. Such results may be related either to formation of new compounds that can react with F-C reagent or to 
enzymatic activity that can be also be affected by plasma treatment [51]. The inactivation of enzymes by plasma treatment has been reported, for instance, for potato polyphenol oxidase [52].

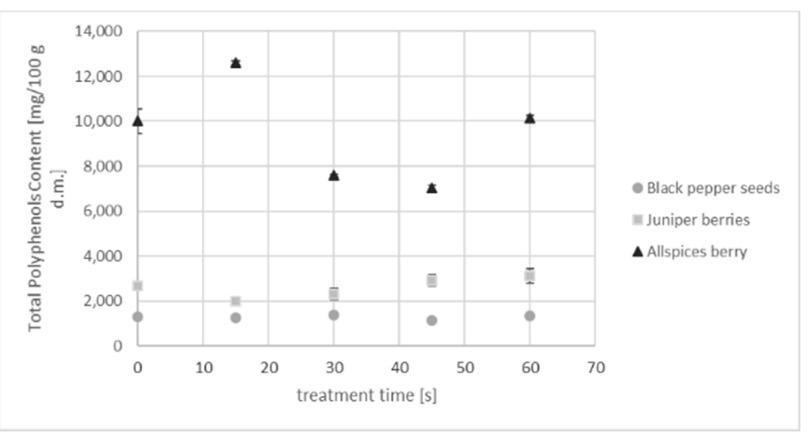

Figure 7. Total polyphenolic content of plasma treated spices.

Antioxidant activity, as measured by the ABTS and DPPH assays is presented in Table 2. The highest antioxidant potential was found for black pepper seeds extracts, regardless of plasma exposition time and assay type. The extract from black pepper seeds plasma treated for $60 \mathrm{~s}$ scavenged $57.6 \%$ and $48.6 \%$ of ABTS and DPPH free radicals, respectively. In turn, the extracts prepared from untreated material exhibited antioxidant activity of 47.0 and $45.9 \%$, as measured by ABTS and DPPH assays, respectively. Interestingly, black pepper seeds contained the smallest amount of phenolics among all analyzed materials despite their antioxidant potential being the highest. Such results may be related to the fact that black pepper contains piperine, as discussed further, which also exhibits antioxidant activity [53]. In general, the most efficient plasma radiation protocol, from an antioxidant activity increment point of view, lasted either a short (15 s) or long (60 s) time. Similar to total phenolics content, such a situation may be either related to modification of structure, degradation of antioxidants and formation of new compounds that exhibit free radical scavenging potential. In turn, the differences between antioxidant activity measured by DPPH and ABTS assays are related to different characteristic of synthetic free radicals. It has been reported previously that ABTS is more useful to reflect antioxidant activity from pigmented and hydrophilic food [54].

Table 2. Antioxidant activity of investigated spices measured by ABTS and DPPH assays.

\begin{tabular}{|c|c|c|c|}
\hline \multirow{2}{*}{ Sample } & \multirow{2}{*}{ Treatment Time [s] } & \multicolumn{2}{|c|}{ Antioxidant Activity [\%] } \\
\hline & & ABTS & DPPH \\
\hline \multirow{5}{*}{ Black pepper seeds } & 0 & $47.03 \pm 1.71 \mathrm{a}$ & $45.91 \pm 1.75 \mathrm{a}$ \\
\hline & 15 & $40.51 \pm 0.45 b$ & $42.19 \pm 1.86 \mathrm{ab}$ \\
\hline & 30 & $51.15 \pm 0.87 c$ & $42.77 \pm 0.41 \mathrm{ab}$ \\
\hline & 45 & $48.14 \pm 0.62 \mathrm{a}$ & $41.53 \pm 1.14 b$ \\
\hline & 60 & $57.60 \pm 1.50 \mathrm{e}$ & $48.61 \pm 2.27 \mathrm{a}$ \\
\hline \multirow{5}{*}{ Juniper berries } & 0 & $30.00 \pm 2.61 \mathrm{~A}$ & $32.91 \pm 0.80 \mathrm{~A}$ \\
\hline & 15 & $28.08 \pm 2.28 \mathrm{~A}$ & $26.16 \pm 1.39 \mathrm{~B}$ \\
\hline & 30 & $29.23 \pm 0.44 \mathrm{~A}$ & $28.76 \pm 0.50 \mathrm{~B}$ \\
\hline & 45 & $33.08 \pm 1.31 \mathrm{~B}$ & $39.03 \pm 1.69 \mathrm{C}$ \\
\hline & 60 & $35.77 \pm 0.33 \mathrm{~B}$ & $42.69 \pm 1.09 \mathrm{C}$ \\
\hline \multirow{5}{*}{ Allspices berries } & 0 & $30.57 \pm 1.85[\mathrm{~A}]$ & $32.47 \pm 1.29[\mathrm{~A}]$ \\
\hline & 15 & $40.83 \pm 0.72[\mathrm{~B}]$ & $47.97 \pm 0.20[\mathrm{~B}]$ \\
\hline & 30 & $24.02 \pm 0.62[\mathrm{C}]$ & $23.42 \pm 3.17[\mathrm{C}]$ \\
\hline & 45 & $24.75 \pm 0.62[\mathrm{C}]$ & $24.47 \pm 0.30[\mathrm{C}]$ \\
\hline & 60 & $36.17 \pm 1.96[\mathrm{D}]$ & $40.53 \pm 2.58[\mathrm{D}]$ \\
\hline
\end{tabular}

Significant differences between investigated samples, based on the Tukey test results, are indicated by different small letters $(a, b, c \ldots)$, capital letters $(A, B, C \ldots)$ or capital letters in brackets $([A],[B],[C] \ldots)$ for different spices species (black pepper seeds, juniper berries and allspices berries, respectively). $n=3$. ABTS - 2,2'-azino-bis(3-ethylbenzothiazoline-6-sulfonic acid; DPPH - 2,2-diphenyl-1-picrylhydrazyl. 


\subsection{Morphology Analysis}

Structural changes of plasma-treated black pepper seeds, as studied by scanning electron microscopy of their cross-section, are visualized in Figure 8. Interestingly, the samples radiated by plasma were characterized by a more compact outer layer of the structure than in untreated material. However, more cavities and open irregularities were present in irradiated material, which was especially visible for samples treated for $60 \mathrm{~s}$. Opposite results were reported by Medvecka et al. [55] who studied the effect of cold plasma on the morphology of allspice berries. In this study, the authors stated that plasma treatment had no impact on the surface of the material. However, the differences may be related to the fact that in the cited experiment, plasma was generated using a coplanar surface barrier discharge method. Despite the gentle character of the plasma treatment, the temperature of these samples also increased up to $40-45^{\circ} \mathrm{C}$.
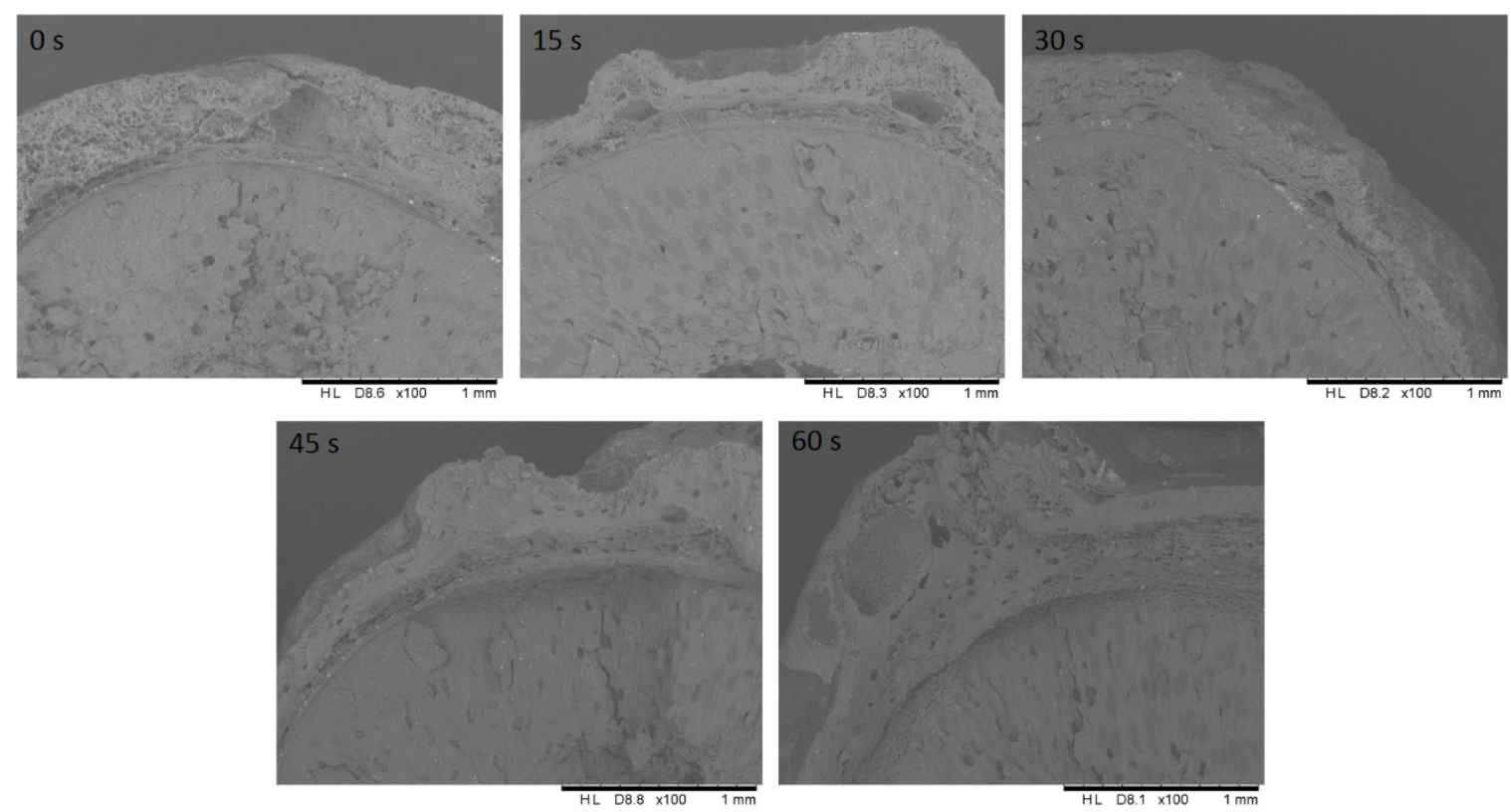

Figure 8. Scanning electron microscope(SEM) images of plasma treated black pepper seeds.

\subsection{Piperine Content in Black Pepper Seeds}

Piperine content (Figure 9) in the investigated black pepper seeds was equal to 5.79-6.94\% d.m and was similar to the values reported previously in the literature (5.61-7.42\%) [56]. Plasma treatment affected the piperine content significantly $(p<0.05)$ only when irradiation time lasted 15 and $30 \mathrm{~s}$. In these cases, its value increased by 13 and $17 \%$, respectively. When microwave plasma application lasted 45 and $60 \mathrm{~s}$, piperine content reached 5.97 and $6.11 \%$, respectively, and the values were the same as in untreated samples from a statistical point of view. The research performed by Hertwig et al. [29] demonstrated that cold plasma treatment, performed both directly and remotely, minimally affected piperine content. It is worth emphasizing that in the case of the cited research, the plasma was generated using either radio frequency (direct application) or microwave (remote application). 


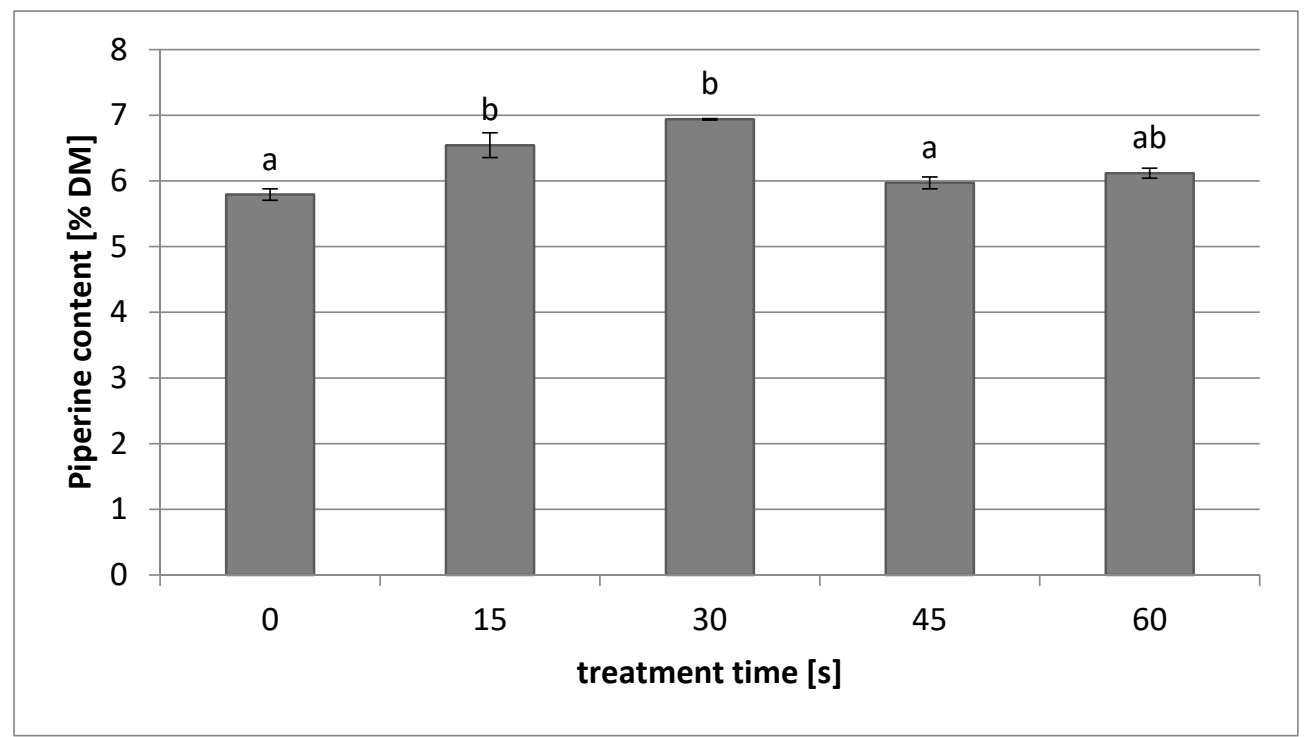

Figure 9. Piperine content in black pepper seeds untreated and treated by microwave plasma for different times. Different letters $(a, b, c \ldots)$ indicate statistically significant difference between samples $(\alpha=0.05)$.

\section{Conclusions}

Microwave-generated plasma treatment can be an interesting alternative for inactivation of molds in spices such as black pepper seeds, juniper and allspices berries. The level of bacterial inactivation depended on treatment time, and no molds were found in samples irradiated for 45 and $60 \mathrm{~s}$. However, bacteria were more resistant and were present even after $60 \mathrm{~s}$ of plasma treatment. The chemical properties of material exposed to 45 and 60 s plasma application were similar, or even better, when compared to intact material. Moreover, the water activity of such treated material decreased, which should positively influence the shelf-life. However, it should be emphasized that color changes of spices treated for 45 and $60 \mathrm{~s}$ were noticeable. Potential reasons for the results may relate to the effects of plasma treatment including generation of reactive chemical compounds and a thermal effect, that can inactivate microorganism and cause other quality changes due to oxidation and thermal degradation. It is worth emphasizing that further research in the field of sensorial properties, or economic analysis, is needed to analyze the feasibility of plasma treatment of spices in industrial conditions.

Author Contributions: Conceptualization, A.W., M.J., and D.W.-R.; methodology, K.R., A.W., M.K., K.K.; formal analysis, A.W., B.H., M.K., K.K. and K.R.; investigation, A.W., B.H., M.K., K.K. and K.R.; resources, M.J.; data curation, A.W., B.H.; writing-original draft preparation, A.W., B.H., M.J., K.K., M.K.; writing-review and editing, A.W., B.H., M.J., K.K., M.K., D.W.-R.; visualization, A.W., B.H., M.K., K.K.; supervision, M.J. and D.W.-R.; project administration, B.H., M.J. All authors have read and agreed to the published version of the manuscript.

Funding: This research was partially supported by The National Science Centre, under the program no. 2015/19/B/ST8/02123.

Conflicts of Interest: The authors declare no conflict of interest. The funders had no role in the design of the study; in the collection, analyses, or interpretation of data; in the writing of the manuscript, or in the decision to publish the results.

\section{References}

1. Kebede, B.; Grauwet, T.; Mutsokoti, L.; Palmers, S.; Vervoort, L.; Hendrickx, M.; Van Loey, A. Comparing the impact of high pressure high temperature and thermal sterilization on the volatile fingerprint of onion, potato, pumpkin and red beet. Food Res. Int. 2014, 56, 218-225. [CrossRef]

2. Kannan, A.; Sandaka, P.G. Heat transfer analysis of canned food sterilization in a still retort. J. Food Eng. 2008, 88, 213-228. [CrossRef] 
3. Lee, H.S.; Coates, G.A. Effect of thermal pasteurization on Valencia orange juice color and pigments. $L W T$ 2003, 36, 153-156. [CrossRef]

4. Lee, H.; Coates, G. Thermal Pasteurization Effects on Color of Red Grapefruit Juices. J. Food Sci. 1999, 64, 663-666. [CrossRef]

5. Saberian, H.; Hamidi Esfahani, Z.; Abbasi, S. Effect of conventional and ohmic pasteurization on some bioactive components of aloe vera gel juice. Iran. J. Chem. Eng. 2015, 34, 99-108.

6. Marszałek, K.; Mitek, M.; Skapska, S. The effect of thermal pasteurization and high pressure processing at cold and mild temperatures on the chemical composition, microbial and enzyme activity in strawberry purée. Innov. Food Sci. Emerg. Technol. 2015, 27, 48-56. [CrossRef]

7. Barba, F.J.; Terefe, N.S.; Buckow, R.; Knorr, D.; Orlien, V. New opportunities and perspectives of high pressure treatment to improve health and safety attributes of foods. A review. Food Res. Int. 2015, 77, 725-742. [CrossRef]

8. Barba, F.J.; Parniakov, O.; Pereira, S.A.; Wiktor, A.; Grimi, N.; Boussetta, N.; Saraiva, J.; Raso, J.; Martín-Belloso, O.; Witrowa-Rajchert, D.; et al. Current applications and new opportunities for the use of pulsed electric fields in food science and industry. Food Res. Int. 2015, 77, 773-798. [CrossRef]

9. Chemat, F.; HumMa, Z.; Khan, M. Applications of ultrasound in food technology: Processing, preservation and extraction. Ultrason. Sonochem. 2011, 18, 813-835. [CrossRef]

10. Pataro, G.; Munoz, A.; Palgan, I.; Noci, F.; Ferrari, G.; Lyng, J. Bacterial inactivation in fruit juices using a continuous flow Pulsed Light (PL) system. Food Res. Int. 2011, 44, 1642-1648. [CrossRef]

11. Niemira, B.A. Cold Plasma Decontamination of Foods *. Annu. Rev. Food Sci. Technol. 2012, 3, 125-142. [CrossRef] [PubMed]

12. Laroussi, M. Low Temperature Plasma-Based Sterilization: Overview and State-of-the-Art. Plasma Process. Polym. 2005, 2, 391-400. [CrossRef]

13. Surowsky, B.; Schluter, O.; Knorr, D. Interactions of Non-Thermal Atmospheric Pressure Plasmawith Solid and Liquid Food Systems: A Review. Food Eng. Rev. 2015, 2, 82-108. [CrossRef]

14. Moisan, M.; Barbeau, J.; Moreau, S.; Pelletier, J.; Tabrizian, M.; Yahia, L. Low-temperature sterilization using gas plasmas: A review of the experiments and an analysis of the inactivation mechanisms. Int. J. Pharm. 2001, 226, 1-21. [CrossRef]

15. Puač, N.; Gherardi, M.; Shiratani, M. Plasma agriculture: A rapidly emerging field. Plasma Process. Polym. 2017, 15, 1700174. [CrossRef]

16. Adamovich, I.V.; Baalrud, S.D.; Bogaerts, A.; Bruggeman, P.J.; Cappelli, M.; Colombo, V.; Czarnetzki, U.; Ebert, U.; Eden, J.G.; Favia, P.; et al. The 2017 Plasma Roadmap: Low temperature plasma science and technology. J. Phys. D Appl. Phys. 2017, 50, 323001. [CrossRef]

17. Wiktor, A.; Śledź, M.; Nowacka, M.; Witrowa-Rajchert, D. Possible applications of low-temperature (cold) plasma in food technology. ŻYWNOŚĆ. Nauka. Technol. 2013, 90, 5-14. (In Polish)

18. Misra, N.; Tiwari, B.; Raghavarao, K.S.M.S.; Cullen, P.J. Nonthermal Plasma Inactivation of Food-Borne Pathogens. Food Eng. Rev. 2011, 3, 159-170. [CrossRef]

19. Hrycak, B.; Czylkowski, D.; Miotk, R.; Dors, M.; Jasiński, M.; Mizeraczyk, J. Application of atmospheric pressure microwave plasma source for hydrogen production from ethanol. Int. J. Hydrogen Energy 2014, 39, 14184-14190. [CrossRef]

20. Patange, A.; Boehm, D.; Ziuzina, D.; Cullen, P.J.; Gilmore, B.; Bourke, P.; Zuizina, D. High voltage atmospheric cold air plasma control of bacterial biofilms on fresh produce. Int. J. Food Microbiol. 2019, 293, 137-145. [CrossRef]

21. Jasiński, M.; Dors, M.; Mizeraczyk, J. Destruction of Freon HFC-134a Using a Nozzleless Microwave Plasma Source. Plasma Chem. Plasma Process. 2009, 29, 363-372. [CrossRef]

22. Yuji, T.; Urayama, T.; Fujii, S.; Mungkung, N.; Akatsuka, H. Temperature behavior of atmospheric-pressure non-equilibrium microwave discharge plasma jets for poly(ethylene naptharate)-surface processing. Surf. Coat. Technol. 2008, 202, 5289-5292. [CrossRef]

23. Czylkowski, D.; Hrycak, B.; Jasinski, M.; Dors, M.; Mizeraczyk, J. Atmospheric pressure microwave microplasma microorganism deactivation. Surf. Coat. Technol. 2013, 234, 114-119. [CrossRef]

24. Mizeraczyk, J.; Dors, M.; Jasiński, M.; Hrycak, B.; Czylkowski, D. Atmospheric pressure low-power microwave microplasma source for deactivation of microorganisms. Eur. Phys. J. Appl. Phys. 2013, 61, 24309. [CrossRef] 
25. Nowakowska, H.; Czylkowski, D.; Hrycak, B.; Jasiński, M. Characterization of a novel microwave plasma sheet source operated at atmospheric pressure. Plasma Sources Sci. Technol. 2018, 27, 085008. [CrossRef]

26. Shimizu, T.; Steffes, B.; Pompl, R.; Jamitzky, F.; Bunk, W.; Ramrath, K.; Georgi, M.; Stolz, W.; Schmidt, H.-U.; Urayama, T.; et al. Characterization of Microwave Plasma Torch for Decontamination. Plasma Process. Polym. 2008, 5, 577-582. [CrossRef]

27. Park, B.J.; Takatori, K.; Sugita-Konishi, Y.; Kim, I.-H.; Lee, J.-H.; Han, D.-W.; Chung, K.-H.; Hyun, S.O.; Park, J.-C. Degradation of mycotoxins using microwave-induced argon plasma at atmospheric pressure. Surf. Coat. Technol. 2007, 201, 5733-5737. [CrossRef]

28. Fröhling, A.; Durek, J.; Schnabel, U.; Ehlbeck, J.; Bolling, J.; Schlüter, O. Indirect plasma treatment of fresh pork: Decontamination efficiency and effects on quality attributes. Innov. Food Sci. Emerg. Technol. 2012, 16, 381-390. [CrossRef]

29. Hertwig, C.; Reineke, K.; Ehlbeck, J.; Knorr, D.; Schlüter, O.K. Decontamination of whole black pepper using different cold atmospheric pressure plasma applications. Food Control 2015, 55, 221-229. [CrossRef]

30. Jasinski, M.; Goch, M.; Mizeraczyk, J. Plasma Device for Treatment of Surface. PL 215139 B1, 31 October 2013.

31. Jasinski, M.; Mizeraczyk, J. Plasma sheet generated by microwave discharge at atmospheric pressure. IEEE Trans. Plasma Sci. 2011, 39, 2136-2137. [CrossRef]

32. Mizeraczyk, J.; Jasiński, M.; Nowakowska, H.; Dors, M. Studies of atmospheric-pressure microwave plasmas used for gas processing. Nukleonika 2012, 57, 241-247.

33. Singleton, V.L.; Rossi, J.A. Colorimetry of total phenolics with phosphomolybdic-phosphotungstic acid reagents. Am. J. Enol. Viticult. 1965, 16, 144-158.

34. Newerli-Guz, J. The antioxidant properties of Spice-Example Black pepper Piper Nigrum L. Bromatol. Chem. Toksykol. 2012, XLV, 887-891. (In Polish)

35. Kř́ž, P.; Petr, B.; Zbynek, H.; Jaromir, K.; Pavel, O.; Petr, S.; Miroslav, D.; Bartos, P.; Havelka, Z.; Kadlec, J.; et al. Influence of Plasma Treatment in Open Air on Mycotoxin Content and Grain Nutriments. Plasma Med. 2015, 5, 145-158. [CrossRef]

36. Selcuk, M.; Oksuz, L.; Basaran, P. Decontamination of grains and legumes infected with Aspergillus spp. and Penicillum spp. by cold plasma treatment. Bioresour. Technol. 2008, 99, 5104-5109. [CrossRef] [PubMed]

37. Kim, J.E.; Lee, D.-U.; Min, S.C. Microbial decontamination of red pepper powder by cold plasma. Food Microbiol. 2014, 38, 128-136. [CrossRef]

38. Purevdorj, D.; Igura, N.; Hayakawa, I.; Ariyada, O. Inactivation of Escherichia coli by microwave induced low temperature argon plasma treatments. J. Food Eng. 2002, 53, 341-346. [CrossRef]

39. Lee, K.-Y.; Park, B.J.; Lee, D.H.; Lee, I.-S.; Hyun, S.O.; Chung, K.-H.; Park, J.-C. Sterilization of Escherichia coli and MRSA using microwave-induced argon plasma at atmospheric pressure. Surf. Coat. Technol. 2005, 193, 35-38. [CrossRef]

40. Baier, M.; Foerster, J.; Schnabel, U.; Knorr, D.; Ehlbeck, J.; Herppich, W.; Schlüter, O. Direct non-thermal plasma treatment for the sanitation of fresh corn salad leaves: Evaluation of physical and physiological effects and antimicrobial efficacy. Postharvest Biol. Technol. 2013, 84, 81-87. [CrossRef]

41. Pasquali, F.; Stratakos, A.C.; Koidis, A.; Berardinelli, A.; Cevoli, C.; Ragni, L.; Mancusi, R.; Manfreda, G.; Trevisani, M. Atmospheric cold plasma process for vegetable leaf decontamination: A feasibility study on radicchio (red chicory, Cichorium intybus L.). Food Control 2016, 60, 552-559. [CrossRef]

42. Ziuzina, D.; Patil, S.; Cullen, P.J.; Keener, K.; Bourke, P. Atmospheric cold plasma inactivation of Escherichia coli, Salmonella enterica serovar Typhimurium and Listeria monocytogenes inoculated on fresh produce. Food Microbiol. 2014, 42, 109-116. [CrossRef] [PubMed]

43. Handorf, O.; Below, H.; Schnabel, U.; Riedel, K.; Ehlbeck, J. Investigation of the chemical composition of plasma-treated water by MidiPLexc and its antimicrobial effect on L. monocytogenes and Pseudomonas fluorescens monospecies suspension cultures. J. Phys. D Appl. Phys. 2020, 53, 305204. [CrossRef]

44. Mokrzycki, W.; Tatol, M. Color difference $\Delta$ E-a survey. Mach. Graph. Vis. 2011, 20, 383-411.

45. Zhang, X.-L.; Zhong, C.-S.; Mujumdar, A.S.; Yang, X.-H.; Deng, L.-Z.; Wang, J.; Xiao, H.-W. Cold plasma pretreatment enhances drying kinetics and quality attributes of chili pepper (Capsicum annuum L.). J. Food Eng. 2019, 241, 51-57. [CrossRef]

46. Lacombe, A.; Niemira, B.A.; Gurtler, J.B.; Fan, X.; Sites, J.; Boyd, G.; Chen, T.H.-H. Atmospheric cold plasma inactivation of aerobic microorganisms on blueberries and effects on quality attributes. Food Microbiol. 2015, 46, 479-484. [CrossRef] 
47. Sarangapani, C.; O'Toole, G.; Cullen, P.J.; Bourke, P. Atmospheric cold plasma dissipation efficiency of agrochemicals on blueberries. Innov. Food Sci. Emerg. Technol. 2017, 44, 235-241. [CrossRef]

48. Won, M.Y.; Lee, S.J.; Min, S.C. Mandarin preservation by microwave-powered cold plasma treatment. Innov. Food Sci. Emerg. Technol. 2017, 39, 25-32. [CrossRef]

49. Wiktor, A.; Śledź, M.; Nowacka, M.; Rybak, K.; Chudoba, T.; Lojkowski, W.; Witrowa-Rajchert, D. The impact of pulsed electric field treatment on selected bioactive compound content and color of plant tissue. Innov. Food Sci. Emerg. Technol. 2015, 30, 69-78. [CrossRef]

50. Tappi, S.; Ramazzina, I.; Rizzi, F.; Sacchetti, G.; Ragni, L.; Rocculi, P. Effect of Plasma Exposure Time on the Polyphenolic Profile and Antioxidant Activity of Fresh-Cut Apples. Appl. Sci. 2018, 8, 1939. [CrossRef]

51. Munekata, P.E.S.; Domínguez, R.; Pateiro, M.; Lorenzo, J.M. Influence of Plasma Treatment on the Polyphenols of Food Products-A Review. Foods 2020, 9, 929. [CrossRef]

52. Kang, J.H.; Roh, S.H.; Min, S.C. Inactivation of Potato Polyphenol Oxidase Using Microwave Cold Plasma Treatment. J. Food Sci. 2019, 84, 1122-1128. [CrossRef] [PubMed]

53. Gülçin, I. The antioxidant and radical scavenging activities of black pepper (Piper nigrum) seeds. Int. J. Food Sci. Nutr. 2005, 56, 491-499. [CrossRef]

54. Flögel, A.; Kim, D.-O.; Chung, S.-J.; Koo, S.I.; Chun, O.K. Comparison of ABTS/DPPH assays to measure antioxidant capacity in popular antioxidant-rich US foods. J. Food Compos. Anal. 2011, 24, 1043-1048. [CrossRef]

55. Medvecká, V.; Mošovská, S.; Mikulajová, A.; Valík, L'.; Zahoranová, A. Cold atmospheric pressure plasma decontamination of allspice berries and effect on qualitative characteristics. Eur. Food Res. Technol. 2020, 1-9. [CrossRef]

56. Newerli-Guz, J.; Śmiechowska, M. Ocena zawartości piperyny w czarnym pieprzu ziarnistym piper nigrum L. Bromatol. Chem. Toksykol. 2009, 42, 827-830.

(C) 2020 by the authors. Licensee MDPI, Basel, Switzerland. This article is an open access article distributed under the terms and conditions of the Creative Commons Attribution (CC BY) license (http://creativecommons.org/licenses/by/4.0/). 